\title{
Free-flap reconstruction in recurrent head and neck cancer: A retrospective review of 124 cases
}

\author{
Hyeong Seop Kim, \\ Chul Hoon Chung, \\ Yong Joon Chang \\ Department of Plastic and \\ Reconstructive Surgery, Hallym \\ University Kangdong Sacred Heart \\ Hospital, Seoul, Korea
}

\begin{abstract}
Background: Free-flap reconstruction for recurrent head and neck cancer may be challenging depending on the previous treatments, those are, chemotherapy, radiotherapy, and surgery, including neck dissection or free tissue transfer. Specifically, the previous treatment could compromise the neck vessels, thereby making free-flap reconstruction more difficult. This study aimed to investigate the correlation between previous treatments and vascular compromise of the free flap.

Methods: In this retrospective study, 124 free-flap reconstructions in 116 patients for recurrent head and neck cancer between 1993 and 2017 were investigated. The demographic characteristics, previous treatments, flap choices, infections, recipient vessels, and vascular crises were evaluated.

Results: Of the 124 reconstruction cases, 10 had vascular crises. There were six revisions, totaling six flap failures. The success rate of free-flap reconstruction for recurrent cancer was $95.2 \%$, which significantly differed from that for primary cancer $(98.8 \%, p=0.006)$. Moreover, in the recurrent cancer group, no correlation was found between previous treatments and vascular crises ( $p>0.05$ ). Increased rates of contralateral or uncommon anastomoses were found following neck dissection $(p<0.05)$.

Conclusion: Previous neck dissection or radiotherapy could lead to scarring and tissue damage, which could in turn make microvascular reconstruction more challenging; however, the effect was not definite in this study. Approximately $60 \%$ of patients with previous neck dissection had compromised ipsilateral recipient vessels, which resulted in contralateral or uncommon anastomoses. In this study, free-flap reconstruction seems to be quite safe and preferable in patients with recurrent head and neck cancer based on the overall survival rate.
\end{abstract}

Keywords: Free tissue flaps / Head and neck neoplasms / Microsurgery / Neck dissection / Second neoplasms

\section{INTRODUCTION}

Reconstruction for tissues of the head and neck region that are altered by any cause must consider the functional aspects, in-

\footnotetext{
Correspondence: Chul Hoon Chung

Department of Plastic and Reconstructive Surgery, Hallym University Kangdong Sacred Heart Hospital, 150 Seongan-ro, Gangdong-gu, Seoul 05355, Korea E-mail: c21ps@hanmail.net

This article was presented at the PRS Korea 2018 on November 10, 2018, in Seoul, Korea.

Received December 3, 2019 / Revised January 17, 2020 / Accepted January 24, 2020
}

cluding respiration, mastication, swallowing, and vocalization, as well as the cosmetic appearance. With recent advances in microsurgery, free-flap reconstruction has become the first-line treatment for head and neck reconstruction because it can improve both functional and cosmetic aspects using tissues from different sites with features similar to those of the defect site. The flap survival rate of head and neck reconstruction using free flaps is reported to be approximately $95 \%-98 \%[1,2]$. Moreover, deficits that require free-tissue transfer are related to the tumor resection in $>97 \%$ of the cases [2]. 
Recurrent tumor at the primary site occurs in approximately $20 \%-30 \%$ of patients with head and neck cancer and remains the most common cause of treatment failure [3-6]. Management of recurrence after surgical resection is challenging. Treatment options include salvage surgery, radiation, chemotherapy, a combination of these therapies, and palliative care. Most head and neck oncologists agree that salvage surgery would provide the best chance of long-term disease control and possible cure for patients with resectable recurrent cancers [4-8]. However, salvage reconstruction for recurrent head and neck cancer may be more challenging because of previous treatment, which may include chemotherapy, radiation, neck dissection, and free-flap reconstruction. Radiotherapy could result in scarring and neck tissue fibrosis [9]. Patients who undergo neck dissection lack potential recipient vessels and have periadventitial scarring and perioperative thrombosis of major vessels [10]. If they had previously undergone free-flap reconstruction, the neck dissection can lead to technical difficulties and a higher chance of tissue damage [11].

Hence, this study aimed to investigate whether previous treatments affect the survival rate of free-flap reconstruction and influence the selection of recipient vessels during salvage surgery using free flaps in patients with recurrent head and neck cancer.

\section{METHODS}

Of a total of 830 cases of free-flap reconstruction in the head and neck region from 1993 to 2017, the medical records of 124 (116 patients) free-flap reconstructions for recurrent head and neck cancer were investigated in this retrospective study. For comparison, 643 patients (647 cases) who had free-flap reconstruction for primary head and neck cancer were assigned to a control group. All of the reconstructive operations were performed by a single experienced reconstructive team to minimize the effects of the learning curve and measurement bias.

Previous treatments included radiotherapy, chemotherapy, concurrent chemo-radiotherapy, wide mass excision excluding neck dissection, wide mass excision including ipsilateral or bilateral neck dissection, and free-flap reconstruction.

Vascular crises were classified according to the cause, which included venous congestion, arterial insufficiency, and carotid blowout. Revision and flap failure cases were categorized according to attempted versus not attempting salvage, and the success rate was confirmed based on the eventual survival of the flap. The total flap success rate of the recurrent cancer group was compared with that of the primary cancer group, and the difference was analyzed in relation to whether the patients in the recurrent cancer group received a previous treatment.
Moreover, the incidence of postoperative infection was evaluated. Infections were classified as either major, which require an operation; or minor infection, which are managed conservatively.

The recipient vessel used in the free-flap reconstruction was identified, and the cases in the recurrent cancer group were categorized into ipsilateral and contralateral anastomosis. If the conventional method could not be performed, such that the

Table 1. Patient characteristics

\begin{tabular}{|c|c|}
\hline Variable & Value $(n=124)$ \\
\hline Age (yr) & $56.6(24-86)$ \\
\hline$\geq 60$ & 56 (45.2) \\
\hline$<60$ & $68(54.8)$ \\
\hline \multicolumn{2}{|l|}{ Sex } \\
\hline Male & 94 (75.8) \\
\hline Female & $30(24.2)$ \\
\hline \multicolumn{2}{|l|}{ Tumor site } \\
\hline Oral cavity & 45 (36.3) \\
\hline Oropharynx & 23 (18.5) \\
\hline Maxilla & $18(14.5)$ \\
\hline Larynx & $15(12.1)$ \\
\hline Hypopharynx & $10(8.1)$ \\
\hline Nasopharynx & $6(4.8)$ \\
\hline Submandibular gland & $4(3.2)$ \\
\hline Parotid gland & $1(0.8)$ \\
\hline Upper lip & $1(0.8)$ \\
\hline Thyroid gland & $1(0.8)$ \\
\hline \multicolumn{2}{|l|}{ Pathology } \\
\hline Squamous cell carcinoma & 107 (86.3) \\
\hline Adenoid cystic carcinoma & $12(9.7)$ \\
\hline Fibromyxoid sarcoma & $2(1.6)$ \\
\hline Papillary carcinoma & $1(0.8)$ \\
\hline Verrucous carcinoma & $1(0.8)$ \\
\hline Melanoma & $1(0.8)$ \\
\hline \multicolumn{2}{|l|}{ Free flaps } \\
\hline Radial forearm & $52(41.9)$ \\
\hline Anterolateral thigh & $48(38.7)$ \\
\hline Fibula & $11(8.9)$ \\
\hline Rectus abdominis & $7(5.6)$ \\
\hline Latissimus dorsi & $6(4.8)$ \\
\hline \multicolumn{2}{|l|}{ T stage } \\
\hline TO & $4(3.2)$ \\
\hline $\mathrm{T} 1$ & $12(9.7)$ \\
\hline T2 & 19 (15.3) \\
\hline T3 & $16(12.9)$ \\
\hline T4 & $73(58.9)$ \\
\hline Overall flap survival & 118 (95.2) \\
\hline
\end{tabular}

Values are presented as mean (range) or number (\%). 
common carotid trunk or vein graft was used, the case was categorized as an uncommon anastomosis. Analysis of the classified recipient vessel group was performed to determine whether differences exist according to history of neck dissection. Pearson chi-square test and analysis of variance were performed, with the significance level set at $p<0.05$. All statistical analyses were conducted using SPSS version 25.0 (IBM Corp., Armonk, NY, USA). This study was approved by the appropriate institutional review board and performed in accordance with the principles of the Declaration of Helsinki. Written informed consent was obtained.

\section{RESULTS}

The mean age of the patients was 56.6 years. Of the 124 patients, 94 were male and 30 were female. The primary tumor site included the oral cavity (45 cases), oropharynx (23 cases), maxilla (18 cases), larynx (15 cases), hypopharynx (10 cases), nasopharynx (6 cases), submandibular gland (4 cases), parotid gland (1 case), upper lip (1 case), and thyroid gland (1 case). In terms of histological classification, 107 cases were squamous cell carcinoma, 12 were adenoid cystic carcinoma, two were fibromyxoid sarcoma, one was papillary carcinoma, one was ver- rucous carcinoma, and one was malignant melanoma. Regarding cancer staging, 73 cases were T4, 16 were T3, 19 were T2, 12 were T1, and four were T0. The type of free-flap used for salvage reconstruction was radial forearm (52 cases), anterolateral thigh (48 cases), fibula osteocutaneous (11 cases), rectus musculocutaneous abdominis (7 cases), latissimus dorsi musculocutaneous (6 cases) (Table 1 ).

Of the 124 cases, 89 (71.8\%) had undergone radiotherapy and 69 (55.6\%) neck dissection (ipsilateral in 40 and bilateral in 29) as the previous treatment. Free-flap reconstruction was performed in 40 (32.3\%) (Table 2), including radial forearm (25 cases), anterolateral thigh (12 cases), fibula osteocutaneous (1 case), and rectus abdominis musculocutaneous free flaps (2 cases) (Table 3 ).

The type of free-flap used for the salvage reconstruction was radial forearm (52 cases), anterolateral thigh (47 cases), fibula osteocutaneous (11 cases), latissimus dorsi musculocutaneous (5 cases), rectus abdominis musculocutaneous ( 7 cases), and jejunal ( 1 case). In one case, anterolateral thigh and pectoralis major musculocutaneous pedicled flaps were simultaneously used for reconstruction of the primary cancer site (Table 4).

The success rate of free-flap reconstruction in patients with recurrent head and neck cancer was $95.2 \%$. Ten cases $(8.1 \%)$ of

Table 2. Previous treatments before salvage operation according to primary sites

\begin{tabular}{|c|c|c|c|c|c|c|c|c|c|c|c|c|c|c|c|c|}
\hline Previous treatment & Tongue & FOM & Buccal & Gingiva & $\begin{array}{l}\text { Hard } \\
\text { palate }\end{array}$ & Tonsil & $\begin{array}{l}\text { Soft } \\
\text { palate }\end{array}$ & ВОТ & $\begin{array}{l}\text { Oro- } \\
\text { pharyngeal } \\
\text { wall }\end{array}$ & RMT & $\begin{array}{l}\text { Naso- } \\
\text { pharynx }\end{array}$ & $\begin{array}{l}\text { Hypo- } \\
\text { pharynx }\end{array}$ & Larynx & Maxilla & Othersa) & Total \\
\hline RTx & & & & 1 & & & & & & & & 2 & 1 & & 1 & 5 \\
\hline CCRT & & & 1 & & & 6 & & 1 & 1 & 1 & 2 & 4 & 2 & 2 & & 20 \\
\hline Operation without ND & 4 & & & & & $1^{\text {b) }}$ & 1 & & 1 & & & & & 3 & & $10(1)$ \\
\hline $\begin{array}{l}\text { Operation without ND } \\
+\mathrm{RTx}\end{array}$ & 1 & & & 1 & & & & & & & 1 & & 2 & 9 & 1 & 15 \\
\hline $\begin{array}{l}\text { Operation without ND } \\
+ \text { +CCRT }\end{array}$ & & & & & & $3^{\text {b) }}$ & & & & & & & & 2 & & $5(1)$ \\
\hline Operation with ND & 3 & 1 & 1 & & & & & & & & & 1 & 2 & & 1 & 9 \\
\hline $\begin{array}{l}\text { Operation with ND } \\
+C T x\end{array}$ & 1 & & & & & & & & & & & & & & 1 & 2 \\
\hline $\begin{array}{l}\text { Operation with ND } \\
+\mathrm{RTx}\end{array}$ & 2 & & 1 & 1 & & & & & & & 1 & & 4 & & 2 & 11 \\
\hline $\begin{array}{l}\text { Operation with ND } \\
+ \text { +CCRT }\end{array}$ & & & & 1 & & & 1 & & & & 1 & & $3^{\text {b) }}$ & 1 & & $7(1)$ \\
\hline Operation with ND\&FF & 6 & $2^{\text {b) }}$ & & & & 1 & & & & & & 2 & & & & $11(1)$ \\
\hline $\begin{array}{l}\text { Operation with ND\&FF } \\
\quad+C T x\end{array}$ & $2^{b)}$ & & & & & & & & & & & 1 & & & & $3(1)$ \\
\hline $\begin{array}{l}\text { Operation with ND\&FF } \\
+\mathrm{RTX}\end{array}$ & 6 & $2^{\text {b) }}$ & 1 & & & 2 & 1 & & & & 1 & & 1 & & & $14(1)$ \\
\hline $\begin{array}{l}\text { Operation with ND\&FF } \\
+ \text { +CCRT }\end{array}$ & 5 & & & 1 & 1 & & & 2 & & 1 & & & & 1 & 1 & 12 \\
\hline Total & 30 & 5 & 4 & 5 & 1 & 13 & 3 & 3 & 2 & 2 & 6 & 10 & 15 & 18 & 7 & $124(6)$ \\
\hline
\end{tabular}

FOM, floor of mouth; BOT, base of tongue; RMT, retromolar trigone; RTx, radiotherapy; CCRT, concurrent chemo-radiotherapy; ND, neck dissection; CTx, chemotherapy; FF, free flap. $\left.{ }^{a}\right)$ Submandibular gland $(n=4)$, parotid gland $(n=1)$, thyroid gland $(n=1)$, upper lip $(n=1)$; ${ }^{b}$ Six cases of total flap failure. 
Table 3. Previous free flap reconstruction according to primary sites

\begin{tabular}{|c|c|c|c|c|c|c|c|c|c|c|c|c|c|c|c|c|}
\hline Previous Free flap & Tongue & FOM & Buccal & Gingiva & $\begin{array}{c}\text { Hard } \\
\text { palate }\end{array}$ & Tonsil & $\begin{array}{c}\text { Soft } \\
\text { palate }\end{array}$ & ВОТ & $\begin{array}{c}\text { Oro- } \\
\text { pharyngeal } \\
\text { wall }\end{array}$ & RMT & $\begin{array}{l}\text { Naso- } \\
\text { pharynx }\end{array}$ & $\begin{array}{l}\text { Hypo- } \\
\text { pharynx }\end{array}$ & Larynx & Maxilla & SMG & Total \\
\hline RF & 13 & 3 & & & & 1 & 2 & 1 & & 1 & & 2 & 1 & & 1 & 25 \\
\hline ALT & 6 & 1 & & & & 2 & 1 & & & & 1 & 1 & & & & 12 \\
\hline Fibula & 1 & & & & & & & & & & & & & & & 1 \\
\hline RA & & & 1 & & & & & & & & & & & 1 & & 2 \\
\hline Total & 20 & 4 & 1 & 0 & 0 & 3 & 3 & 1 & 0 & 1 & 1 & 3 & 1 & 1 & 1 & 40 \\
\hline
\end{tabular}

FOM, floor of mouth; BOT, base of tongue; RMT, retromolar trigone; SMG, submandibular gland; RF, radial forearm; ALT, anterolateral thigh; RA, rectus abdominis.

Table 4. Free flaps for salvage reconstruction according to primary sites

\begin{tabular}{|c|c|c|c|c|c|c|c|c|c|c|c|c|c|c|c|c|}
\hline Free flap & Tongue & FOM & Buccal & Gingiva & $\begin{array}{l}\text { Hard } \\
\text { palate }\end{array}$ & Tonsil & $\begin{array}{l}\text { Soft } \\
\text { palate }\end{array}$ & ВОТ & $\begin{array}{c}\text { Oro- } \\
\text { pharyngeal } \\
\text { wall }\end{array}$ & RMT & $\begin{array}{l}\text { Naso- } \\
\text { pharynx }\end{array}$ & $\begin{array}{l}\text { Hypo- } \\
\text { pharynx }\end{array}$ & Larynx & Maxilla & Others ${ }^{a)}$ & Total \\
\hline RF & 9 & 1 & 1 & 1 & 1 & $7^{\text {b) }}$ & 3 & 1 & 2 & 1 & 3 & 7 & 9 & 5 & 1 & $52(1)$ \\
\hline ALT & $13^{\text {b) }}$ & $3^{\text {b) }}$ & 2 & 1 & & $4^{\text {b) }}$ & & 2 & & 1 & 2 & 2 & $6^{\text {b) }}$ & 7 & 4 & $47(4)$ \\
\hline Fibula & 5 & $1^{\text {b) }}$ & & 2 & & 1 & & & & & & & & & 2 & 11 (1) \\
\hline LD & & & & 1 & & & & & & & 1 & & & 3 & & 5 \\
\hline RA & 3 & & & & & 1 & & & & & & & & 3 & & 7 \\
\hline Jejunal & & & & & & & & & & & & 1 & & & & 1 \\
\hline ALT+PMMC & & & 1 & & & & & & & & & & & & & 1 \\
\hline Total & 30 & 5 & 4 & 5 & 1 & 13 & 3 & 3 & 2 & 2 & 6 & 10 & 15 & 18 & 7 & $124(6)$ \\
\hline
\end{tabular}

FOM, floor of mouth; BOT, base of tongue; RMT, retromolar trigone; RF, radial forearm; ALT, anterolateral thigh; LD, latissimus dorsi; RA, rectus abdominis; PMMC, pectoralis major myocutaneous.

a)Submandibular gland $(n=4)$, parotid gland $(n=1)$, thyroid gland $(n=1)$, upper lip $(n=1)$; bix cases of total flap failure.

Table 5. Clinical factors relative with vascular crisis

\begin{tabular}{lccc}
\hline Clinical factor & No. (\%) & Vascular crisis & $p$-value ${ }^{\text {a) }}$ \\
\hline $\begin{array}{l}\text { Previous radiotherapy } \\
\text { Yes }\end{array}$ & $89(71.8)$ & 7 & 0.897 \\
No & $35(28.2)$ & 3 & \\
Previous neck dissection & & & 0.780 \\
Yes & $69(55.6)$ & 6 & \\
No & $55(44.4)$ & 4 & \\
Previous free flap & & & 0.585 \\
Yes & $40(32.3)$ & 4 & \\
No & $84(67.7)$ & 6 & \\
\hline
\end{tabular}

${ }^{a}$ Chi-square test.

vascular crisis were noted: five cases of venous congestion, two cases of arterial insufficiency, and three cases of carotid artery blowout. Moreover, revision was performed in six of the 10 cases, with successful salvage in only four. Thus, a total of six cases (4.8\%) had total flap failure (i.e., 4 where revision was not possible and 2 with failed revision). The success rate in the control group, i.e., the patients with primary head and neck cancer, was 98.8\%; of 647 cases, only eight (1.2\%) developed total flap failure. A statistically significant difference in success rates between the control and recurrent cancer groups was observed $(p=0.006)$.

The analysis examining the association of vascular crises with previous radiotherapy, neck dissection, or free-flap reconstruction demonstrated no statistically significant relationship $(p>0.05)$ with any of these treatments (Table 5).

Postoperative infection occurred in 51 cases (41.1\%), with 30 being major infections requiring an operation. The operations performed included incision and drainage (4 cases), debridement and closure (8 cases), skin grafting (3 cases), pedicled flap reconstruction ( 8 cases), additional free-flap reconstruction ( 2 cases), and pharyngostoma formation (1 case). Moreover, two cases of vascular revision for carotid blowout due to infection were successfully salvaged, while two patients who developed systemic infection, which required various operative procedures, died. Minor infection occurred in 21 cases and was treated conservatively.

We further evaluated whether a previous neck dissection influenced the selection of the recipient artery for arterial anastomosis. Seventy-three patients received an anastomosis between the primary tumor site and the ipsilateral neck artery, of which 27 had undergone previous neck dissection and 46 had not. Twenty-nine patients received a contralateral side anastomosis (Fig. 1), of which 23 had undergone previous neck dissection and six had not. Moreover, 19 patients had a direct anastomosis of the artery to the common carotid trunk as the conventional 

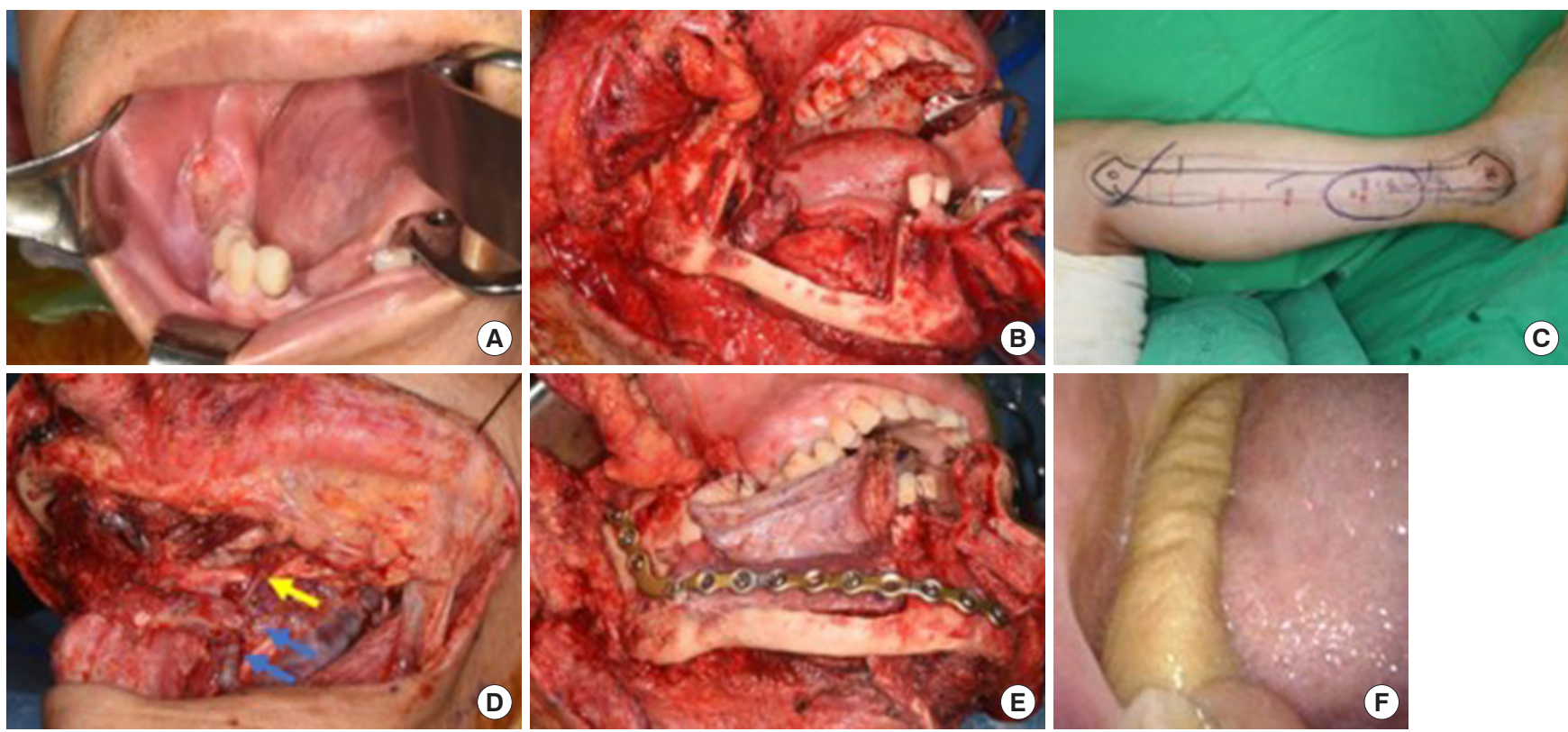

Fig. 1. A 59-year-old man with recurrent squamous cell carcinoma at the right lower gingiva. (A) Preoperative photograph. (B) Intraoperative photograph after wide excision and marginal mandibulectomy. (C) A fibular osteocutaneous free-flap was planned. (D) Microscopic anastomosis was performed on the left side, which is contralateral to the tumor site. The yellow arrow indicates the end-to-end anastomosis of the peroneal artery to the left facial artery, while the blue arrows indicate the end-to-end anastomosis of venae comitantes to the branches of the left internal jugular vein. (E) Fixing of the vascularized fibula bone graft with a reconstruction plate. (F) Appearance of the flap at 1 year postoperatively.
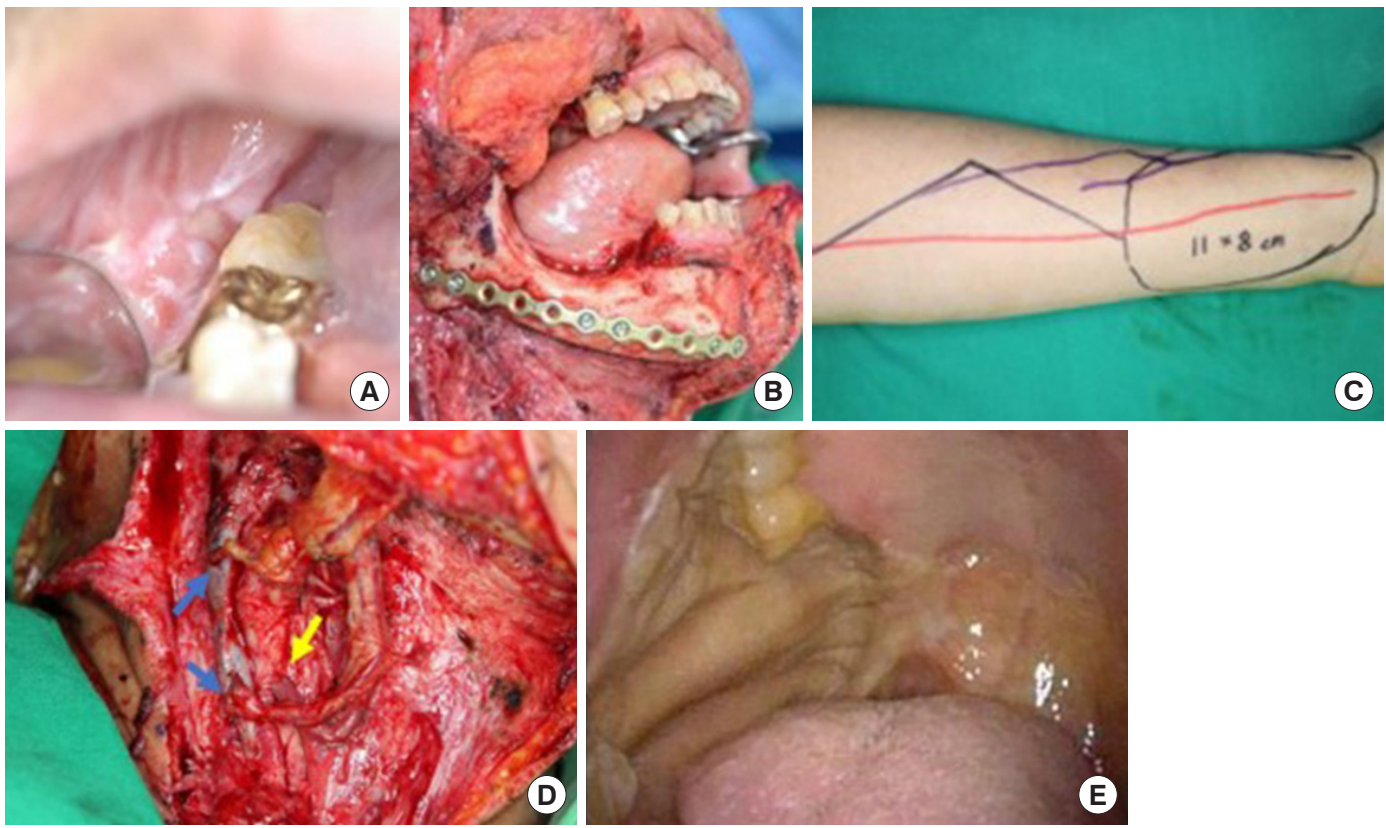

Fig. 2. A 65-year-old man with recurrent squamous cell carcinoma at the right lower gingiva. (A) Preoperative photograph. (B) Intraoperative photograph after wide excision and marginal mandibulectomy. (C) A radial forearm free-flap was planned. (D) The yellow arrow indicates the end-to-side anastomosis of the radial artery to the right common carotid artery, while the blue arrows indicate the end-to-side anastomoses of venae comitantes to the right internal jugular vein. (E) Appearance of the flap at 4 years postoperatively.

recipient vessel could not be used (Fig. 2), and three involved a vein graft for the venous anastomosis (Fig. 3). There were no cases of vein graft use for the arterial anastomosis. Of the 22 cases of uncommon anastomosis, 19 were in patients that had undergone neck dissection and only three were in those that had not. Statistical analyses confirmed that a higher percentage 

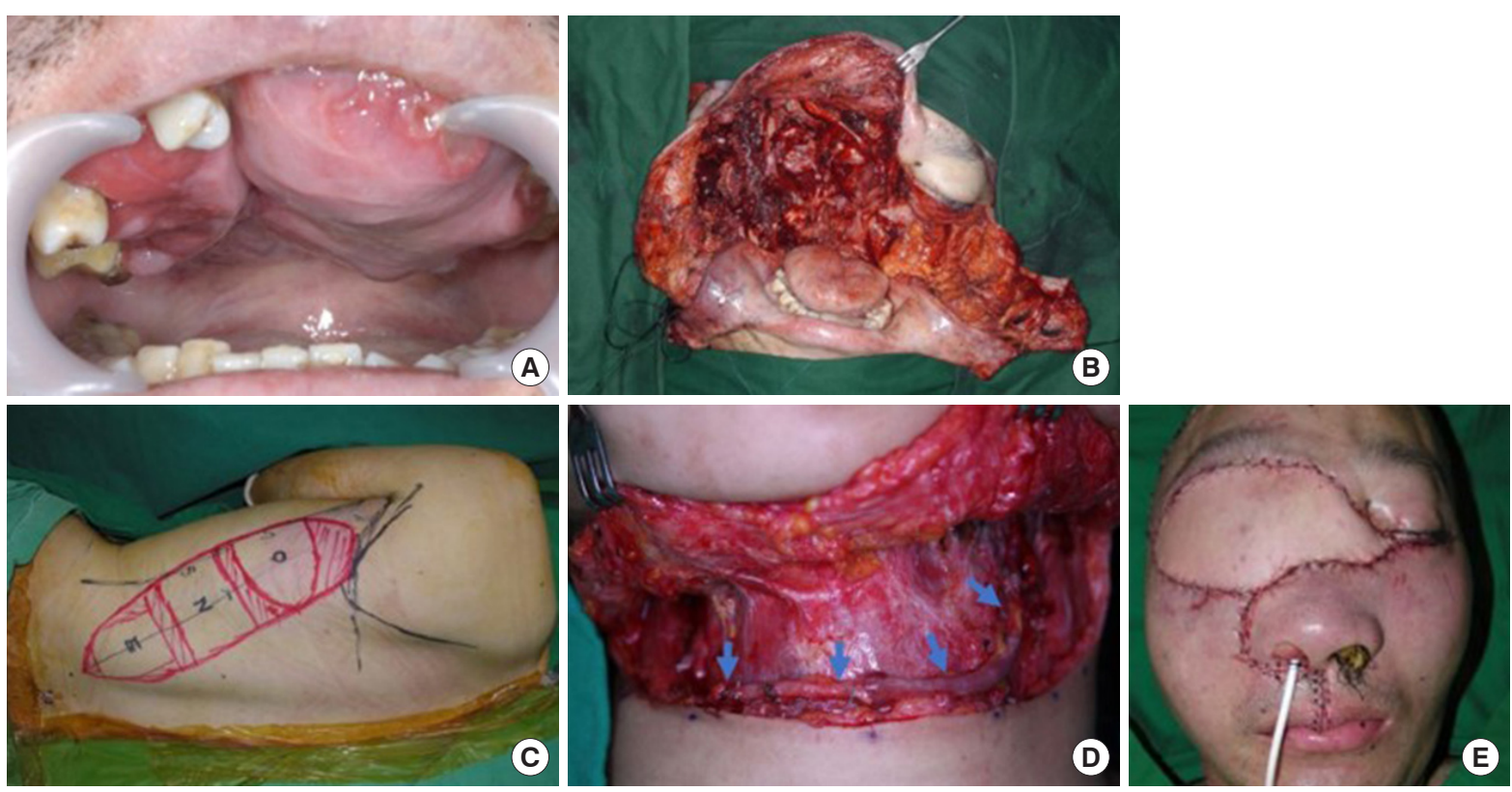

Fig. 3. A 41-year-old man with recurrent adenoid cystic carcinoma at the right maxilla and palate. (A) Preoperative photograph. (B) Intraoperative photograph after both radical maxillectomy and right orbital exenteration. (C) A latissimus dorsi free-flap was planned. (D) The endto-side anastomosis of the thoracodorsal artery to the left facial artery was performed, while a greater saphenous vein graft to the left external jugular vein was placed due to thrombosis of the right internal and external jugular veins. Blue arrows indicate the greater saphenous vein graft. (E) Immediate postoperative appearance.

of reconstructions in patients with a previous neck dissection involved contralateral or uncommon anastomoses $(p<0.05)$.

\section{DISCUSSION}

Whether previous treatments could influence surgical outcomes of salvage reconstruction for recurrent head and neck cancer remains to be clearly established. In this study, we found no significant effect of previous treatments, such as radiotherapy $(p=0.897)$, neck dissection $(p=0.78)$, or free-flap reconstruction ( $p=0.585$ ), on the overall flap survival rate. This finding is consistent with the results of previous studies [9-16]. Nevertheless, a statistically significant difference $(p=0.006)$ in the success rate of free-flap reconstruction was observed between the control group (98.8\%) and the recurrent cancer group (95.2\%). This could be explained by the fact that complicating factors (i.e., multiple comorbidities, advanced cancer stage, postoperative infection, or poor general condition) may have affected the outcome of patients in the recurrent cancer group, despite the little influence of a particular previous treatment on overall flap survival. In previous studies, the success rate of free-flap reconstruction for recurrent head and neck cancer was approximately $92 \%-96 \%[9,11-13,15]$; thus, the flap survival rate of $95.2 \%$ in our study seems to be a comparatively reasonable outcome.

A considerable difference in the selection of the recipient ar- tery was found between those with and those without previous neck dissection. A tendency to perform the arterial anastomosis at the contralateral side was noted in the $60.8 \%$ of patients who had previous neck dissection $(p<0.05)$, which is in agreement with the finding in previous studies. Head et al. [10] demonstrated that in patients with previous neck dissection, the recipient vessel is located at the contralateral side in approximately $61 \%$ of cases. Tan et al. [16] also found a statistical significance in the frequent selection of contralateral neck vessels during neck dissection.

Furthermore, 22 cases of uncommon anastomosis were analyzed, of which 19 had end-to-side arterial anastomosis at the carotid trunk and three used vein grafts for venous anastomosis. No cases involved a vein graft for arterial anastomosis, owing to the fact that when the pedicle is short, end-to-side arterial anastomosis is performed at the ipsilateral carotid trunk to reduce the usage of vein grafts, and that venous anastomosis is inevitably performed when using vein grafts to connect the opposite side. Based on the results of the statistical analysis in our study, previous neck dissection increased the frequency of contralateral side anastomosis as well as unconventional procedures, such as direct carotid trunk anastomosis or vein grafting $(p<0.05)$. Although a previous study reported a few cases of end-to-side anastomosis at the carotid artery, our study is the first to consider the actual clinical significance [10].

In this study, four vein grafts were used for the venous anasto- 
mosis in three cases; however, neither flap failures nor revisions were observed. Nevertheless, numerous studies reported that using a vein graft for free-flap reconstruction could increase vascular compromise and cause flap failure $[10,17,18]$. Some studies recommended cephalic vein transposition in lieu of a vein graft if there is no recipient vein in the neck region $[2,10,15]$. However, Furr et al. [19] showed that various factors, such as radiation therapy, prior neck dissection, and prior freeflap reconstruction, could increase the demand for vein grafts; nevertheless, whether the use of a vein graft could independently influence flap survival remains unclear. Furthermore, Hanasono et al. [14] suggested that a vein grafts only be used when absolutely necessary and that extremely lengthy grafts be avoided.

Mucke et al. [20] stated that previous neck dissection could affect microvascular revision and could result in total flap failure, which could be attributed to inadvertent vascular injury and ligation of potential recipient vessels. However, the authors failed to mention whether significant differences in the use of neck vessels (i.e., ipsilateral or contralateral) between those with and those without neck dissection were found. Instead, they recommended that the use of contralateral neck vessel be avoided because it could prolong the duration of the operation, the additional dissection in the opposite neck could increase the risk of morbidity, and the risk of kinking or compression of the vein may increase as the length of the vascular pedicle becomes longer.

Postoperative infection occurred in 51 cases (41.1\%), with 30 being major infections requiring an operation. We believe that this is because patients that develop recurrent cancer and multiple comorbidities become more vulnerable to infection, require long operation times due to this being a secondary procedure, and receive pre- or postoperative radiotherapy or chemotherapy, which can result in immunosuppression. Hence, free-flap reconstruction in patients with recurrent cancer must carefully consider their preoperative status and the history of infection. Moreover, during the operation, aseptic techniques should be strictly observed and prolonged operations avoided. Following the operation, signs of infection should be monitored and appropriate antibiotics must be prescribed; proactive infection control could be achieved by operative intervention, if necessary. The time to recurrence after treatment of the primary cancer ranged from 2 to 180 months, with an average of 33.2 months. The average time of recurrence according to the primary tumor site was 29.9 months for oral cavity tumors, 35.2 months for oropharynx tumors, 35.7 months for maxilla tumors, 32.3 months for larynx tumors, 34.7 months for hypopharynx tumors, 35.3 months for nasopharynx tumors, and 28.8 months for submandibular gland tumors. There was no significant difference according to the primary site $(p>0.05)$. In terms of histologic type, the average time to recurrence for squamous cell carcinoma was 31.4 months while that for adenoid cystic carcinoma was 38.3 months. There was no significant difference according to cancer histology $(p>0.05)$.

Based on the results of this study, the following strategies for salvage reconstruction using free flaps in patients with recurrent head and neck cancer could be applied: if the patient had undergone previous neck dissection that resulted in severe periadventitial scarring or perioperative thrombosis in the ipsilateral neck vessel, the contralateral vessel should be utilized. In such cases, a flap with a long vascular pedicle should be used, if possible, to reduce the use of vein grafts; however, a vein graft may be inevitable in some cases. Moreover, if there is no suitable contralateral vessel, end-to-side anastomosis at the carotid trunk could be attempted. In addition, if a single free-flap reconstruction does not provide enough coverage, especially in cases with a large volume deficit or multiple defects, a concurrent pedicled flap, such as pectoralis major musculocutaneous or latissimus dorsi musculocutaneous flaps, could be considered. As there is a high chance of surgical site infection, appropriate pre- and postoperative management is critical. Infection could result in vascular crises, such as carotid blowout; thus, careful management is essential.

\section{NOTES}

\section{Conflict of interest}

No potential conflict of interest relevant to this article was reported.

\section{Ethical approval}

The study was approved by the Institutional Review Board of Hallym University Kangdong Sacred Heart Hospital (IRB No. 2019-10-002) and performed in accordance with the principles of the Declaration of Helsinki. Written informed consents were obtained.

\section{Patient consent}

The patients provided written informed consent for the publication and the use of their images.

\section{ORCID}

Hyeong Seop Kim https://orcid.org/0000-0003-4037-2805

Chul Hoon Chung https://orcid.org/0000-0003-3722-1838

Yong Joon Chang https://orcid.org/0000-0003-4966-6543 


\section{REFERENCES}

1. Wu CC, Lin PY, Chew KY, Kuo YR. Free tissue transfers in head and neck reconstruction: complications, outcomes and strategies for management of flap failure. Analysis of 2019 flaps in single institute. Microsurgery 2014;34:339-44.

2. Zhang C, Sun J, Zhu H, Xu L, Ji T, He Y, et al. Microsurgical free flap reconstructions of the head and neck region: Shanghai experience of 34 years and 4640 flaps. Int J Oral Maxillofac Surg 2015;44:675-84.

3. Goodwin WJ Jr. Salvage surgery for patients with recurrent squamous cell carcinoma of the upper aerodigestive tract: when do the ends justify the means? Laryngoscope 2000;110(3 Pt 2 Suppl 93):1-18.

4. Kim AJ, Suh JD, Sercarz JA, Abemayor E, Head C, Funk G, et al. Salvage surgery with free flap reconstruction: factors affecting outcome after treatment of recurrent head and neck squamous carcinoma. Laryngoscope 2007;117:1019-23.

5. Wong LY, Wei WI, Lam LK, Yuen AP. Salvage of recurrent head and neck squamous cell carcinoma after primary curative surgery. Head Neck 2003;25:953-9.

6. Taussky D, Dulguerov P, Allal AS. Salvage surgery after radical accelerated radiotherapy with concomitant boost technique for head and neck carcinomas. Head Neck 2005;27:182-6.

7. Kowalski LP. Results of salvage treatment of the neck in patients with oral cancer. Arch Otolaryngol Head Neck Surg 2002;128:58-62.

8. Tan HK, Giger R, Auperin A, Bourhis J, Janot F, Temam S. Salvage surgery after concomitant chemoradiation in head and neck squamous cell carcinomas: stratification for postsalvage survival. Head Neck 2010;32:139-47.

9. Bengtson BP, Schusterman MA, Baldwin BJ, Miller MJ, Reece GP, Kroll SS, et al. Influence of prior radiotherapy on the development of postoperative complications and success of free tissue transfers in head and neck cancer reconstruction. Am J Surg 1993;166:326-30.

10. Head C, Sercarz JA, Abemayor E, Calcaterra TC, Rawnsley JD, Blackwell KE. Microvascular reconstruction after previous neck dissection. Arch Otolaryngol Head Neck Surg 2002;128:
328-31.

11. Amin AA, Baldwin BJ, Gurlek A, Miller MJ, Kroll SS, Reece GP, et al. Second free flaps in head and neck reconstruction. J Reconstr Microsurg 1998;14:365-8.

12. Klug C, Berzaczy D, Voracek M, Enislidis G, Rath T, Millesi W, et al. Experience with microvascular free flaps in preoperatively irradiated tissue of the oral cavity and oropharynx in $303 \mathrm{pa}-$ tients. Oral Oncol 2005;41:738-46.

13. Klug C, Berzaczy D, Reinbacher H, Voracek M, Rath T, Millesi $\mathrm{W}$, et al. Influence of previous radiotherapy on free tissue transfer in the head and neck region: evaluation of 455 cases. Laryngoscope 2006;116:1162-7.

14. Hanasono MM, Barnea Y, Skoracki RJ. Microvascular surgery in the previously operated and irradiated neck. Microsurgery 2009;29:1-7.

15. Arce K, Bell RB, Potter JK, Buehler MJ, Potter BE, Dierks EJ. Vascularized free tissue transfer for reconstruction of ablative defects in oral and oropharyngeal cancer patients undergoing salvage surgery following concomitant chemoradiation. Int J Oral Maxillofac Surg 2012;41:733-8.

16. Tan NC, Lin PY, Chiang YC, Chew KY, Chen CC, Fujiwara T, et al. Influence of neck dissection and preoperative irradiation on microvascular head and neck reconstruction: analysis of 853 cases. Microsurgery 2014;34:602-7.

17. Inbal A, Silva AK, Humphries LS, Teven CM, Gottlieb LJ. Bridging the gap: a 20-year experience with vein grafts for free flap reconstruction. The odds for success. Plast Reconstr Surg 2018;142:786-94

18. Maricevich M, Lin LO, Liu J, Chang EI, Hanasono MM. Interposition vein grafting in head and neck free flap reconstruction. Plast Reconstr Surg 2018;142:1025-34.

19. Furr MC, Cannady S, Wax MK. Interposition vein grafts in microvascular head and neck reconstruction. Laryngoscope 2011;121:707-11.

20. Mucke T, Rau A, Weitz J, Ljubic A, Rohleder N, Wolff KD, et al. Influence of irradiation and oncologic surgery on head and neck microsurgical reconstructions. Oral Oncol 2012;48:36771. 